\title{
USING A GRAPE HARVESTER IN SUPER-INTENSIVE OLIVE CULTIVATION
}

\author{
Francesco Bellomo, Paola D’Antonio
}

\section{Introduction}

The only way to censure economic sustainability in the olive-growing sector in agricultural areas of great validity, but where farms are small and the situation is aggravated by the additional problem of finding farmhands, is by cutting production costs.

Manpower is nowadays a factor limiting the possibility of agricultural production in small areas where crops have a production cycle characterised by distinct phases, such as pruning and harvesting, which require a lot of manpower concentrated in a short period of time.

This situation is true of grape- and olive-growing and therefore the availability on the market of multifunctional machinery has given a strong input to the economic recovery of these crops in many agricultural areas; the possibility of using techniques and machines on different cultivation cycles has been a further contribution to re-growth in sectors where the drop in sales caused by the emergence of products from new markets has been particularly pronounced.

It is evident that the difficult task of research must now be directed towards optimising the operating capacities of this machinery, in both technical and economic terms.

The present research derives from these considerations, and the aim was to evaluate the technical and economic aspects of using a grape harvester for superintensive olive cultivation. The research followed two directions; one was linked to the possibility of using a machine on several cultivation cycles, and the other was linked to the introduction of new and more intensive cultivation systems with a greater number of trees per hectare.

Paper received 12.01.2007; accepted 07.03.2008

Prof. Francesco Bellomo, Associate Professor, Dipartimento per la Progettazione e Gestione Sistemi Agro-Zootecnici e Forestali, Sezione di Meccanica Agraria, Università degli Studi di Bari.

Prof. Paola D'AnTonio, Associate Professor, Dipartimento Tecnico-Economico per la Gestione del Territorio Agricolo-Forestale Università degli Studi della Basilicata.
These two aspects of the research are directly correlated because the grape harvester can only be used for olives if the plantation has been set up to allow space for the movement of the machinery and to facilitate the action of the collection equipment. The best form of cultivation may be defined as a wall system with particularly low distances between trees, and so high plant density per hectare and greater production; these features contribute to the definition of this production system as being super-intensive [1] [2].

This research represents a part of the experimental work carried out in collaboration with Prof. Angelo Godini of the Plant Production Science Dept. of the Faculty of Agriculture of Bari, within the research project entitled "Experimentation of new cultivation systems for oil olives", financed by the Banca di Credito Cooperativo of Cassano delle Murge and Tolve [4] [5]. The machine-harvesting trials were conducted in the experimental super-intensive olive plantation at Cassano delle Murge (Bari Province), set up for the purpose of this research (Fig. 1), and using the "NEW HOLLAND-Braud SB56" grape harvester modified for use in a super-intensive olive plantation [3] [6].

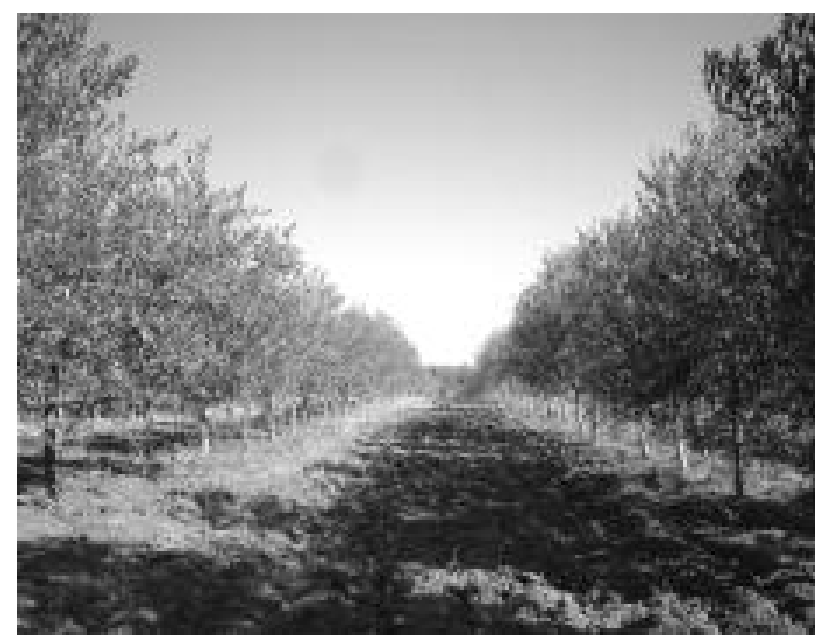

Fig. 1 - Experimental plantation. 


\section{Materials and Methods}

\subsection{Characteristics of the olive field}

In the super-intensive olive field set up in the country near the town of Cassano delle Murge (Bari Province) in spring 2002, the Spanish cultivars Arbequina and Arbosana were compared with 6 Italian cultivars, Cipressino, Coratina Frantoio, fs-17, Leccino and Urano [4]. The aim was to evaluate the physiological response of each cultivar to the type of cultivation system, both in terms of productivity and in terms of suitability for the use of a harvester. The first results of agronomical behaviour of tested cultivars are reported in paper [5].

The tree distance was $4.0 \mathrm{~m} \times 1.5 \mathrm{~m}$, with a plant density of about 1667 plants per hectare. A structure was raised consisting of top poles and dividers, three horizontal rows and in order to contain the upright bearing of the well-defined central axis, in the first two years the plant was supported by a wooden or bamboo frame ( $\varnothing$ 18-20), and a galvanised iron wire espalier was erected for the plant to rest on.

The high number of plants per hectare and the need for a water supply to obtain greater yields and better quality olives justify the use of a localised distribution drip irrigation system with a $24 / 26 \mathrm{~mm}$ diameter drip arm per row and $4 \mathrm{l} / \mathrm{h}$ drippers. The irrigation shifts were fixed at 2 sessions a week with a volume of 16 $\mathrm{mc} / \mathrm{ha}$. It is evident that while irrigation was always concentrated in the autumn-spring period, it meant that different seasonal irrigation volumes were recorded in the three years it was in use, due to differing climatic situations.

The cost of the plantation with these characteristics, including working the soil before planting, the cost of the plants and frames, the irrigation system and the crops produced in the first year, may range from 5000 to $6000 € /$ ha, depending on whether the espalier is made up of 1 or 2 wires.

Pruning work was carried out in the first four years to train the plants onto the wires, creating a tree with a central axis and secondary branches suitable for harvesting by machinery, and this was done as follows:

1 - From the first year onwards, the treetops were repeatedly tied to the frame as they grew, in order to ensure that the central axis was vertical;

2 - In the second and third years of life, the vegetation at below $40 \mathrm{~cm}$ was eliminated and inserted directly on the central axis so as to create the best possible conditions for movement and use of the harvester.

\subsection{Technical characteristics of the harvester}

The NEW HOLLAND-Braud mod.SB56 harvester used during the trials (Fig. 2) has a controlled dynamism and harvesting system (S.D.C.), and a pannier system for containing the olives.

The picking head consist of suitably shaped bars of very flexible plastic fitted to the two ends. While the shaker rods move horizontally sideways, they bend but remain the same distance apart from each other. The horizontal shaking movement is determined by a control mechanism which varies cyclically and alternately the curve of the shakers so that one row is at maximum curvature while the other row is at minimum curvature.

A novelty of the S.D.C. system is the possibility of three different settings for the sideways movement of the shaker rods, which increases the efficiency of the entire harvesting system; another feature is the possibility of regulating the distance between the trunk guides from 18 to $25 \mathrm{~cm}$ in order to work on plants at different stages of development.

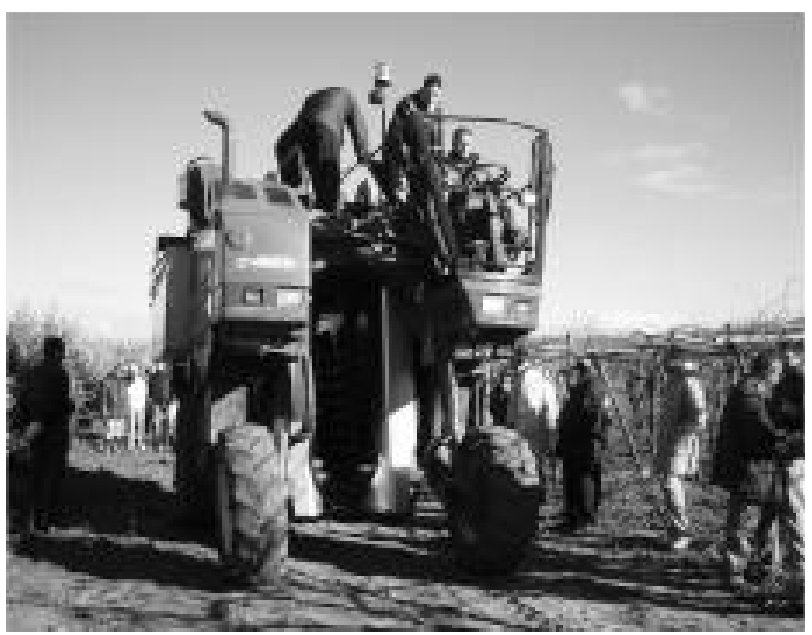

Fig. 2 - NEW HOLLAND-Braud mod.SB56.

The pannier collection system (Fig. 3) patented by Braud consists of two wheels holding 62 soft panniers in food-grade polyurethane.

The wheels are activated by a hydraulic motor and slide directly on a stainless steel guide at the same speed as that of the forward movement, but in the opposite direction, so that the panniers remain still, enveloping the bottom part of the olive trunks and so preventing damage by gouging or scraping.

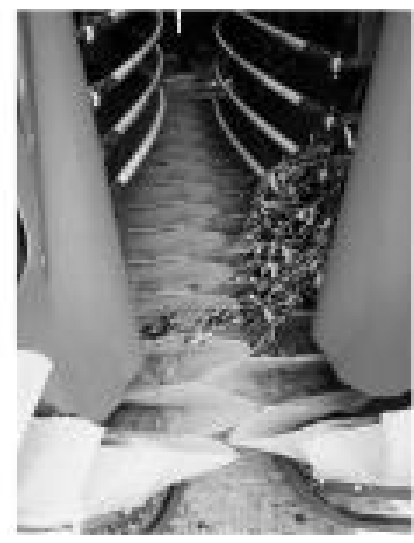

Fig. 3 - Pannier collection system. 


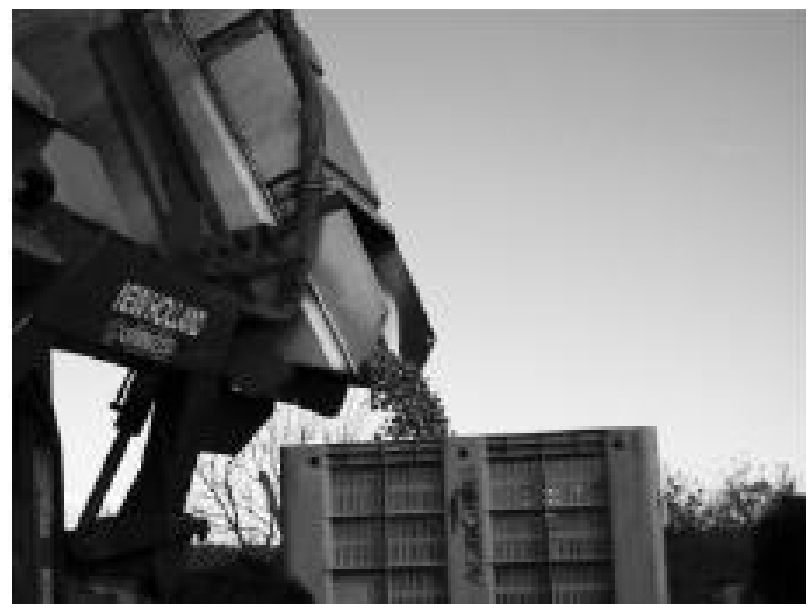

Fig. 4 - Emptying the bin.

The panniers are capable of collecting olives at only $15 \mathrm{~cm}$ from the ground without any difficulty, regardless of the quality of the product. This system ensures perfect collection without any losses caused by olives falling to the ground.

The olives are cleaned firstly by two aspirators located on two sides at the base of the collection tube; at the top, two more aspirators complete the process, removing the leaves from the drupes before they are transferred into the bins. All the aspirators have shoot cutters.

It is possible to choose the ideal bin capacity from 1050, 1300 and 1600 litres, which means that a maximum total capacity of 3200 litres can be achieved (Fig. 4)

All components of the collection system are made of noble materials: stainless steel, polyurethane and PVC, to conserve the oil quality.

The main modification made to a traditional machine harvester set up for grape-harvesting are (Fig. 5):

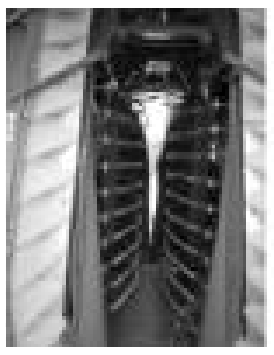

(a)

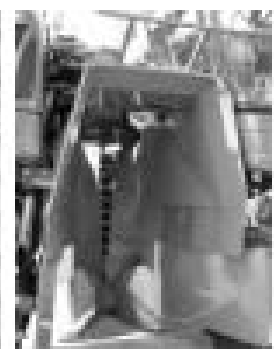

(b)

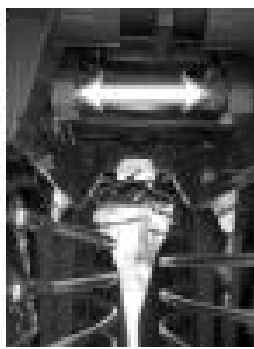

(c)
Fig. 5 - Modifications

(a) number of shakers, (b) conveyor, (c) tube adjustment.

1. extended shaker rods

2. addition of a conveyor at the front

3. adjustment of the width of the collection tube.

The shaker rods are extended because the productive part of a super-intensive olive tree is about 2,00 m high, which makes it necessary to have 10-11 pairs of shakers for maximum harvesting efficiency.

The addition of a conveyor in front of the collection tube makes it easy for the to enter the collection equipment, and prevents congestion which can damage both the plant and the machine.

It is necessary to widen the collection tube because the vegetation of the plantation becomes wider over time.

\subsection{Field tests}

The harvesting trials (Fig. 6) in the superintensive at fourth farm year with the grape harvester were carried out in 2005 in order to evaluate its performance in terms of operating capacity and harvesting efficiency. Predisposition of each cultivar to detachment from the tree was also verified. This performance was then compared to that of hand-held shaker rods, the only equipment that could be used in that plantation. The comparison also included the harvesting costs in order to establish the economic limits of using the grape harvester in a super-intensive olive plantation, in comparison with manual harvesting and with the equipment mentioned.

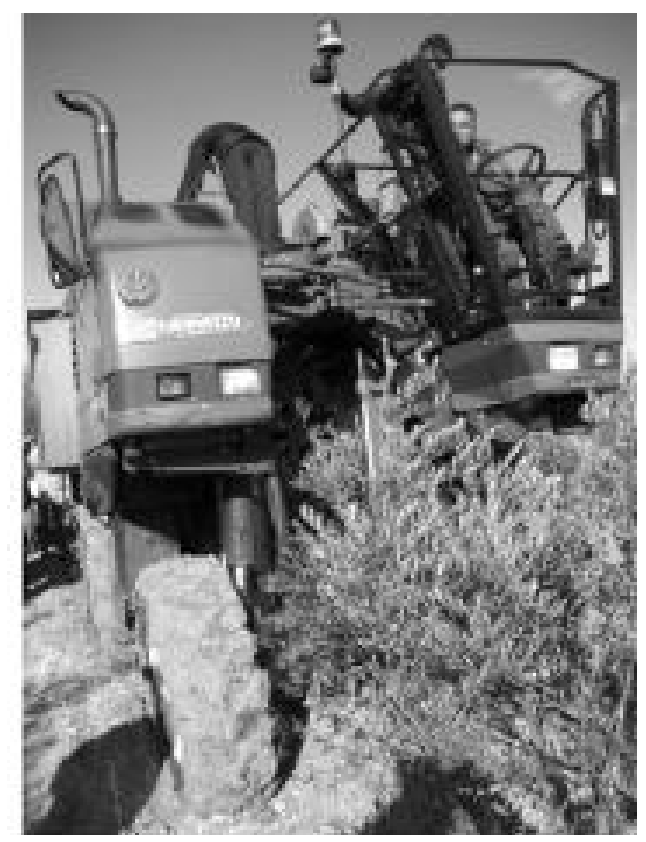

Fig. 6 - Harvester at work.

In order to have a complete evaluation of performance and harvesting costs of the grape-harvester, the comparison was also extended to include shaker machines operating in a traditional plantation. It must be emphasised that a study of the economic feasibility of a super-intensive plantation harvested using a grape harvester compared to a traditional plantation harvested by a shaker may be carried out by taking into account all the parameters which affect the overall production costs for these plantations. 


\section{Results and considerations}

The harvesting trials showed that no significant difference was found among tested cultivars concerning detachment from the tree. Harvesting efficiency was very positive because all cultivars responded well to the machine, providing $98 \%$ harvesting efficiency, while losses on the plant, intended as drupes which were not detached from the plant and so not intercepted by the machin, was $2 \%$.

Table 1 shows the results of the trials. The reported data represent the averages obtained from trials carried out for each cultivar.

\begin{tabular}{|l|c|}
\hline Forward speed $(\mathrm{km} / \mathrm{h})$ & 1.7 \\
\hline Operating capacity $(\mathrm{ha} / \mathrm{h})$ & 0,50 \\
\hline Workers (n) & 2 \\
\hline Harvesting efficiency $(\%)$ & 98 \\
\hline Losses on plant (\%) & 2 \\
\hline Operable surface (ha) & 175 \\
\hline
\end{tabular}

TABLE 1 - Grape harvester operational data.

All cultivars presented notable vertical growth of the foliage, with flexibility in the treetops, which caused no problems for the grape harvester. One future problem for some cultivars such as Coratina, Frantoio and Leccino could be the sideways development of the foliage in the space between rows, which if unchecked could cause branches to be broken and stripped of their bark.

During the harvesting trials, the forward speed of the harvester was $1,7 \mathrm{~km} / \mathrm{h}$, and in this way the operating capacity was $0,5 \mathrm{ha} / \mathrm{h}$. The best result concerning the quantity of harvested olives was obtained for the Arbosana cultivar, which had at trial time a yield of almost $4000 \mathrm{~kg} / \mathrm{ha}$. In this case the operating capacity in terms of harvested olive quantity is 2000 $\mathrm{kg} / \mathrm{h}$. But clearly it can increase considerably with the production per hectare, how it was shoved in tests carried out in superintensive growing with a greater production [7].

As regards the organisation of manpower, there were two farm-workers, one who drove the machine, and the other who took care of unloading. The big reduction in the number of workmen was possible thanks to the good manoeuvrability of the machine which gave excellent results in this plantation, as it advanced between the rows, while turning and also when unloading the product.

In order to give an overall evaluation of the use of this machine it is necessary to estimate a fundamentally important parameter, which is the growing surface of minimum convenience; the definition of this parameter will lead to a definition of optimum use of the machine [8].

It is evident that in order to calculate the growing surface of minimum convenience it will be necessary to acquire data about the cost of the machine, manpower costs, plantation productivity and unit cost of the product. All of this must refer to specific agricultural areas, because the different parameters vary from one socio-economic situation to another.

Referring data to plantations around the Apulia Region (Italy) growing surface of minimum convenience was estimated for olive plantations with different average yields which varied between 3000 and 15000 $\mathrm{kg} / \mathrm{ha}$. The surfaces were 35 ha for minimum yield and 8 ha for maximum yield. The minimum convenience surface was calculated with reference to a completely manual harvest or one carried out using nonmotorized hand-held equipment. The comparison for evaluating the machine's technical and economical feasibility should also include the use of other equipment which can be used in the same type of olive plantation for mechanised harvesting.

Analysis of the different harvesting machines on the market leads to the conclusion that the only machines which can be used successfully in a super-intensive plantation are the hand-held motorised tools such as the shaker rods which are driven by an electric, pneumatic or combustion motor, because it is almost impossible to move other kinds of machines easily in an olive plantation where there are small plants which are very close together.

Since all these kinds of equipment have a very low working capacity and therefore also can cover only a much smaller surface than the grape harvester, the comparison was made using a number of tools able to equal the surface operable by the grape harvester, estimated at 175 ha.

Analysis of the work data concerning the tools mentioned has made it possible to establish that in order to equal the grape harvester's performance it takes:

- 9 electric motor hand-held vibrating comb shakers with 19 to 31 workmen

- 8 pneumatic motor hand-held vibrating comb shakers with 16 to 28 workmen

- 7 internal combustion motor hand-held vibrating hook shakers with 15 to 27 workmen.

The number of workmen used was considered variable with production, which in this kind of plantation can reach quite high levels in some years. In this case we supposed variable yields of 3000 to $15000 \mathrm{~kg} / \mathrm{ha}$.

The minimum convenience surface was calculated for these plantations and for the plantation using the grape harvester, and the harvest costs were calculated according to the surface and the yield. The harvest cost was then expressed as a percentage of the cost of manual harvesting and shown on the graph in relation to the surface harvested.

A single curve was considered for the electric and pneumatic tools, as they had the same harvesting costs. Figure 7 shows the graphs which refer to average yields of 3000,9000 and $15000 \mathrm{~kg} / \mathrm{ha}$

From the graphs it can be seen that: 
- The use of hand-held motorised tools which behave very similarly makes it possible to obtain lower harvesting costs than manual harvesting, even with relatively small surfaces, while the grape harvester gives a reduced percentage only starting from 35 ha for low yields and 8 ha for high yields.

- The cost of harvesting with a grape-harvester becomes lower than that of the other tools from a surface of about 80 ha for low yields, 60 ha for medium-high yields and 40 ha for high yields.

- The graphs all show the same decreasing trend with greater variation in the smaller surfaces. It can be seen that, as with low yields, the grape harvester makes it possible to obtain harvesting costs which are much lower than the other machines when the surface is increased, even when starting from greater surface of minimum convenience. This must be due to the fact that the labour costs remain the same although the surface varies.

- The optimum use of the grape harvester, that is to say on a surface near to its operating capacity and with medium-high yields, makes it possible to bring down harvesting costs by more than $80 \%$ in comparison with manual harvesting and $50 \%$ in comparison with other machinery.

Since the olive-growing sector includes many variations in production systems, it would be interesting and necessary at this point to extend the comparison of feasibility of one production system with another to include the higher level of mechanisation which is possible with these. This comparison is made more difficult by the fact that the agronomic behaviour of super-intensive farming is significantly different from all other traditional plantations. At present, in superintensive farming the average productive life of a tree is no more than 20 years, in contrast with the traditional plantations which span the centuries.

Moreover, the data which are available at the moment make it possible to see that a super-intensive plantation already gives significant yields in its third year and usually gives average yields which are higher than those of other plantations. It is therefore necessary to carry out an extended economic study over a relatively long period so as to evaluate the feasibility of the super-intensive system where a grape-harvester is used in comparison with other highly-mechanised systems.

However, in order to be able to evaluate the grapeharvester's performance from a technical perspective in comparison with other machines used for harvesting olives, we chose to compare it with the most commonly used and most complete harvesters, such as shaker machinery. In order to make the comparison more significant, the use of the shaker was hypothesised in a traditional olive plantation which is quite common in Apulia, with a tree distance of $10 \times 10 \mathrm{~m}$, and a yield of $9000 \mathrm{~kg} / \mathrm{ha}$ equal to the yield considered for the super-intensive system.

The shaker is used when sheets are spread on the ground to catch the olives. This is still the most wide- spread machinery, despite the advent of harvesting carts and umbrella shakers which have not really reduced the harvesting costs and cannot be adapted for use in all plantations. The operational data for the shaker are shown in Table 2. From these data it can be seen that the grape harvester working in the super-intensive system has an operating capacity and an operable surface which is double that of the shaker operating in the olive plantation considered. This means that the product harvested in the time unit will also be double, in the case of a yield of $9000 \mathrm{~kg} / \mathrm{ha}$ about $4500 \mathrm{~kg} / \mathrm{h}$. For this reason, two shakers are needed to equal the performance of one grape-harvester.
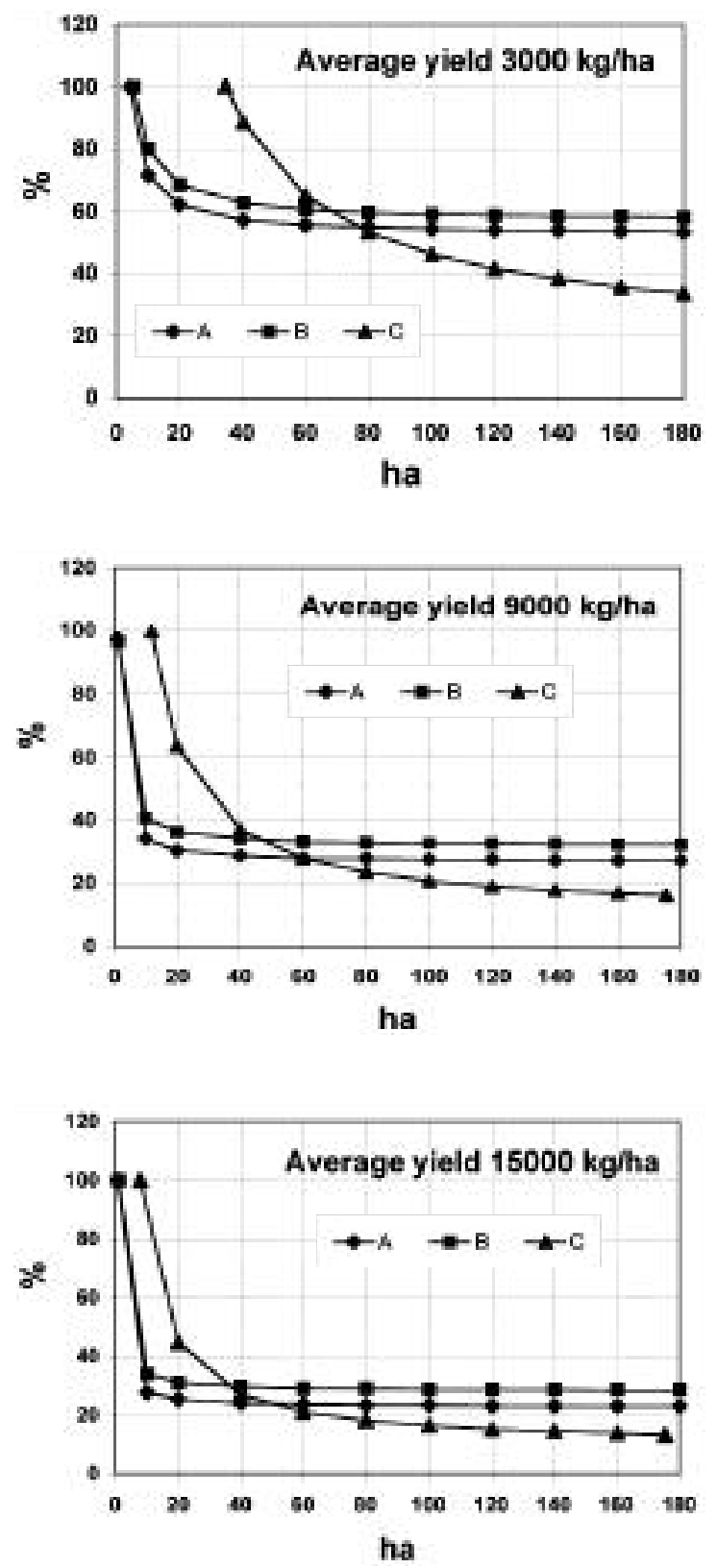

Fig. 7 - Cost of harvesting with grape-harvester and employable tools in superintensive, as a percentage of cost of manual harvesting, related to surface area.

A- Electric or pneumatic motor hand-held vibrating comb shakers B- Internal combustion motor hand-held vibrating hook shakers C- Grape-harvester 


\begin{tabular}{|l|c|}
\hline Operating capacity (ha/h) & 0.25 \\
\hline Workers (n) & 13 \\
\hline Harvesting efficiency (\%) & 95 \\
\hline Losses on plant (\%) & 5 \\
\hline Operable surface (ha) & 88 \\
\hline
\end{tabular}

TABLE 2 - Olive Harvesting Shaker operational data.

Analysis of the harvesting costs makes it possible in both cases to calculate the minimum convenience surface in comparison with manual harvesting and to construct a graph (Fig. 8) showing the harvest cost trends for the grape harvester and shaker in relation to the surface.

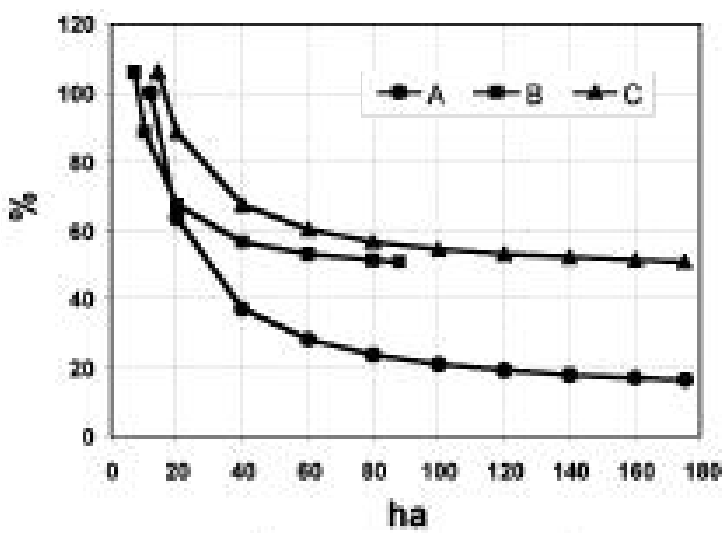

Fig. 8 - Harvesting costs of grape harvester and shaker, as a percentage of manual harvest cost,. related to surface area.

A - Grape-harvester

B - One shaker

C - Two shakers

Here again the costs are expressed as a percentage of the manual harvesting costs. In order to present a better comparison, we have shown data relating to the use of one and of two shakers.

From the graph it can be seen that the use of the grape harvester in a super-intensive system has a greater minimum convenience surface (12 ha against 7 ha), but gives lower harvesting costs than a shaker in a traditional plantation, when the surface exceeds 20 ha. As the surface increases, so does the difference between harvesting costs, until with an area over 80 ha the harvesting costs of the grape harvester are less than half those of the shaker.

Therefore, the grape harvester gives decidedly better performances than the shaker from the technical point of view, because it has a great operating capacity with just two workmen, and costs much less than manual harvesting or harvesting by other machines available at present.

As already mentioned, for an overall comparison between super-intensive and traditional plantations it remains to be verified whether the margins of cost reduction for harvesting make it possible to cover eventual greater expenses for the plantation and its management, also taking into account the possible average annual yield increases obtainable with super-intensive farming. This is the case for new plantations, because the comparison is much more difficult with the conversion of old plantations, and in most cases it is out of the question.

Future research will be directed with this in mind, and in the initial stage will seek to identify the olivegrowing areas which are most representative of the Mediterranean basin, in order to refer all the data of the necessary parameters to these areas.

\section{Conclusions}

The experimentation carried out, supported by the background information and data obtained from European and American situations where super-intensive olive farming is now the only system for growing olives, makes it possible to express the following considerations.

The plantation established to facilitate use of the grape harvester responds well to the action of the shakers, and the product is completely intercepted by the harvesting system of the machine.

The frequency setting of the shakers was of vital importance, and in this case was 450-500 shakes/min and therefore identical with the setting used when the harvesting machine is used in a vineyard.

This frequency must take account of the greater or lesser elasticity of the plant - a characteristic of each cultivar - and its posture; it is necessary to adjust the machine for each type of plantation so as to ensure that the product is completely intercepted.

Due to the very satisfactory working capacity of $0,5 \mathrm{ha} / \mathrm{h}$ which was achieved in optimum plantation conditions and branch and product positioning, it is possible to harvest even very large plantations quickly with reduced manpower.

There are various reasons why the fact that manpower can be reduced to a minimum is a definite advantage of using the grape harvester in a super- intensive olive plantation. Firstly, the cost of employing workers to operate the machine is reduced to the minimum possible of just 2 units, so that it is less of a problem to find workers in situations where manpower is absorbed by other non-agricultural sectors. Then, the vast amount of time which is usually spent on trying to hire workers is saved.

The harvested product is clean; there are practically no leaves or branches in the hopper, which means that the fans in the machine clean the product efficiently, that the cultivation system is suitable, and that the harvester is able to pass between the rows without causing any damage to the plants.

Therefore the product is clean, whole and above all dry, when it arrives at the olive oil factory, and the quality is such as to allow higher prices and give better quality products derived from it.

These plantations are in continual expansion and 
this will make it possible to check the response of this cultivation system in other areas with production techniques and cultivation which often are quite different. Most importantly, it will be possible to evaluate the productivity times in these plantations. Today we know that harvesting can take place from the third leaf, but we do not know how long these plantations remain productive. The oldest plantation in the world in production at the moment is 12 years old, and still gives excellent yields.

Good agronomic and cultivation practices will ensure balanced development of the plant's vegetation, but the productive life of the plant in this new type of cultivation system may only be evaluated directly as the years go by.

From the comparison with the other commonlyused harvesting machines it can be seen that from the technical point of view the grape harvester has a much higher working capacity, with minimum use of manpower; this remains the same although yield increases. The harvesting costs are lower than for other machinery for surface areas varying from 30 to 80 hectares, depending on the yield.

In any case there is the important advantage that it requires very low levels of manpower for a relatively large surface area, while the other machines need a large number of workmen which has to increase with specific yields, even when much lower working capacity is obtained.

Of course, in some agricultural situations where the average farm is quite small, the medium-high levels of the minimum convenience growing surface justify the use of the grape-harvester only in association with other growers, or hiring a machine; this solution is a good compromise to the introduction of mechanisation in olive plantations, keeping one of its positive aspects which is that of being able to go into the plantation and harvest without all the preliminary business of choosing and hiring workers, a procedure which makes it impossible to proceed immediately with the work of harvesting.

\section{References}

[1] Godini A., Bellomo F., Olivicoltura superintensiva in Puglia per la raccolta meccanica con vendemmiatrice, Atti Convegno Internazionale di Olivicoltura - Celebrazione del Centenario dell'Istituto Sperimentale per la Olivicoltura, Spoleto, 22-23 Aprile 2002, 230-234.
[2] Tous J., Romero A., Plana J., Plantaciones superintensivas en olivar. Comportamiento de 6 variedades". Agricoltura, (2003), E - 851: 346-350.

[3]Bellomo F., D' Antonio P., Le prove di raccolta meccanica effettuate con l'impiego della vendemmiatrice. analisi tecnica ed economica" (Spagna, quando l'olivicoltura è superintensiva) - Rivista "Olivo e Olio" - Il Sole 24 Ore-Edagricole-Bologna, (2003), Anno VI novembre/dicembre, 8-13.

[4] Godini A., Bellomo F., Cultivar spagnole d'olivo ed impianti superintensivi. Terra e Vita, (2004), n. 50, 81-82.

[5] Godini A., Palasciano M., Ferrara G., Camposeo S., Prime osservazioni sul comportamento agronomico di cultivar di olivo allevate con il modello superintensivo, Frutticoltura, (2006), n. 3, 40-44.

[6] Arrivo A., Bellomo F., D’Antonio P., Raccolta meccanica di un oliveto superintensivo, Rivista L'Informatore Agrario, (2006), LXII, n. 1, 68-71.

[7] MATEU J., New high-density olive orchards in the World. The total mechanization, Agromillora Catalana S.A.Adelaide - October $12^{\text {th }} 2002$.

[8] Arrivo A., Bellomo F., D’Antonio P., Limiti di convenienza per l'impiego delle macchine operatrici, applicazione a macchine mono e polifunzionali per la viticoltura, Rivista di Ingegneria Agraria, (2001), Anno XXXII, Numero 3, 147-157.

\section{SUMMARY}

This paper reports the first results of experimental mechanical harvesting tests in a super-intensive olive cultivation. In this type of olive cultivation, trees were grown with a central axis mode and a tree distance of 4,00x1,50 m. A "Braud" grape harvesting machine for espalier vineyards was used in an experimental olive grove in Cassano delle Murge. On the basis of harvesting tests it was possible to verify that the harvesting machine is able to detach the almost all the product with an operative work capacity of $0,5 \mathrm{ha} / \mathrm{h}$. An evaluation of harvesting cost was carried out to determine the minimum convenience growing surface, and also to estimate the increase in income per hectare which could be achieved using mechanised harvesting as opposed to manual harvesting. Moreover, in order to determine the economic limits of using the grape harvester, its performance was compared with that of other harvesting machines used in both super-intensive and traditional plantations.

Key words: harvesting, mechanical, olive, superintensive. 
